\title{
Aphallia: An Extremely Rare Congenital Anomaly. Report of Two Cases
}

\author{
Pradyumna Pan* \\ Pediatric Surgery Unit, Ashish Hospital and Research Centre, Jabalpur, Madhya Pradesh, India \\ *Corresponding Author: Pradyumna Pan, Pediatric Surgery Unit, Ashish Hospital and Research Centre, Jabalpur, Madhya Pradesh, \\ India.
}

Received: July 15, 2019; Published: August 27, 2019

\begin{abstract}
Aphallia or penile agenesis is a rare malformation associated with no phallus, abnormality of the urogenital system and uncompromising psychological after effects. We describe 2 patients who presented at the age of 4 years and 19 years with penile agenesis, a well-developed scrotum and normal sized testes.
\end{abstract}

Keywords: Absent Penis; Penile Reconstruction; Phalloplasty

\section{Introduction}

Aphallia is a very rare congenital anomaly with an estimated incidence of 1 in 10 million. About a hundred cases have been reported in the literature so far. In the $4^{\text {th }}$ week of embryogenesis penile agenesis is supposed to be due to inadequate development of the genital tubercle or its failure to progress into a penis with the absence of corpora cavernosa and spongiosum [1]. The karyotype is characteristically XY. The scrotum is typically developed normal. The testes are usually well developed with normal testosterone secretion in response to human chorionic gonadotropin stimulation. In majority, the urethral opening is located in the perineum between the scrotum and anus or as a fistula to the anoectum. Skoog and Belman proposed three variants postsphincteric, presphincteric and urethral atresia depending on the urethral position in correlation to the anal sphincter [2].

\section{Case 1}

The parents of a 4 years old presented with a complaint of an absence of penis since birth and passing urine per rectally. He was born at term to a non-consanguineous, primi mother by vaginal delivery. There was no family history of other congenital anomalies. Clinical examination showed a good general state, an absence of penis with well-developed scrotum and bilaterally descended testes (Figure 1). The anus was in normal position with wrinkled tissue in the perineum. The abdomen X-ray, USG abdomen and echocardiography were normal. Upon inspection of the anal orifice, urine was seen to come out of the fistula near the anal verge. No abnormality was detected on per rectal examination. Discussion with parents was done and all the alternatives of treatment accessible were given but the patient was lost to follow up.

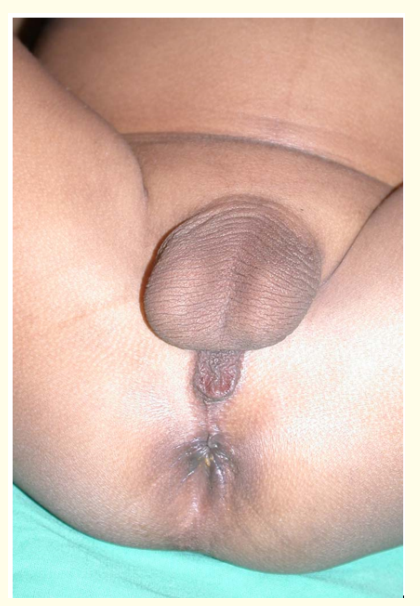

Figure 1: Clinical photo of the child 


\section{Case 2}

A 19 year old male, born in a poor tribal family with no significant birth and childhood medical history attended hospital for the first time with absent penis since birth and recurrent fever. There was no other distinguishable external anomaly. The scrotum was well developed with bilateral normally descended testes (Figure 2). The urethral opening was located on the anterior rectal wall, about $1.5 \mathrm{~cm}$ from the anal verge. Severe hydrouretronephrosis with significant diminished left renal cortical thickness was identified in abdominal ultrasonography. Pelvis showed typical anatomy and no female internal organs was visualised. Cystourethrography was performed under sedation which revealed an anterior located urethrorectal fistula, a short urethra and vesicoureteral reflux (Figure 3). Urinalysis showed loaded pus cells. Due to reflux and UTI, patient was started on urinary chemoprophylaxis. The patient and his parents' preferred male gender and was advised for penile reconstruction and urethroplasty. The patient lost to follow up.

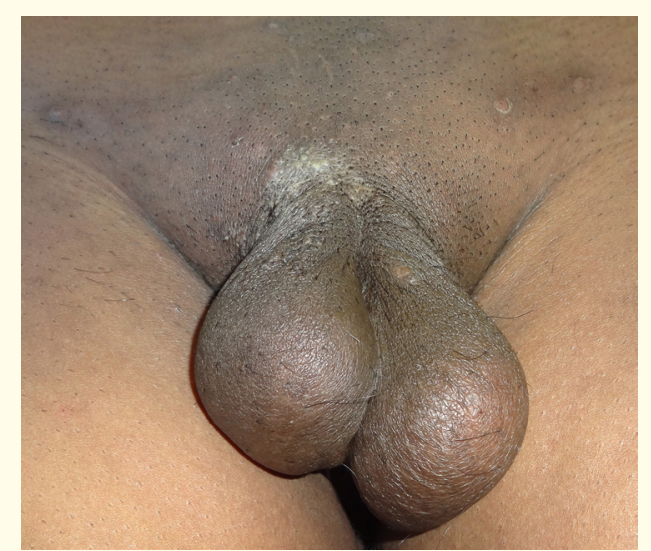

Figure 2: Clinical photo showing absence of penis with well-developed scrotum and testes.

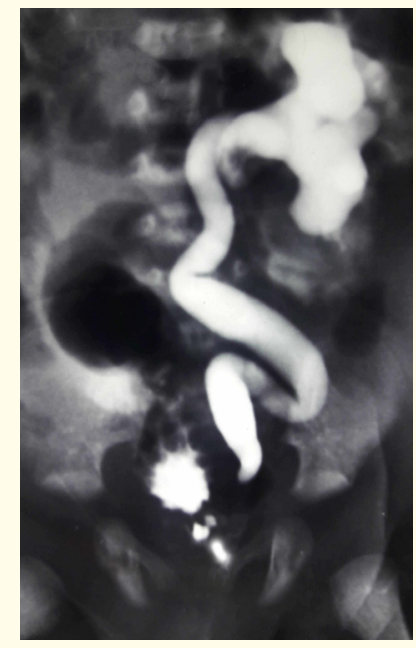

Figure 3: Cystography showing reflux (grade 5), small contracted bladder and short urethro-rectal communication.

\section{Discussion}

Gender reassignment should be done in the neonatal period, or else, it is personalized according to age at presentation, sex of bringing up, psychological evaluation of child and judgment of the family. The orthodox management consisted of urethral perineal transposition, early bilateral orchiectomy with the conservation of the scrotal skin and feminizing genitoplasty in the neonatal period or at the time of presentation. Early reconstruction helps the family to accept the neonate's gender status. The vaginoplasty is carried out at the time of puberty along with estrogen therapy, for breast development and other female secondary sexual characters. However, androgens stimulation on the brain, cause a male psychosocial and psychosexual character causing gender dysphoria in later life. Taking into account of recent advances, it seems reasonable that neophalloplasty be looked upon as the preferred approach for the child born with aphallia.

Male gender assignment involves phalloplasty as addressed by Hage., et al. in 1993, that is to provide an aesthetically acceptable phallus in a single stage procedure, creation of a neourethra allowing voiding in erect posture, tactile and erogenous sensibility, sufficiently bulky to accommodate a prosthesis and insignificant scarring with no functional loss in the donor area [3]. Phallic reconstruction to treat aphallia is a challenging endeavor. Accessible procedures are recommended for older children or after puberty. Early phalloplasty has a number of issues like an absence of further development and the large neo-phallus being an encumbrance to the youthful kid. To diminish parental anxiety and psychosocial improvement of the child Bajpai., et al. [4] used the scrotal flap to form a makeshift neophallus and urethroplasty during childhood followed by neophalloplasty in the adolescent period.

There are many surgical options for phalloplasty like Pedicled groin flaps, Radial forearm free flap, Anterolateral thigh flap, Myocutaneous latissimus dorsi Flap, Fibula osteocutaneous flap and de Castro technique [5]. The discussion stays with respect to the job of neophalloplasty, whether to give self-sexual delight or aberrant joy by enabling the partner to encounter a normal sexual relationship. Rigidity required for penetration is a crucial component of the ideal phalloplasty, consequently, penile prosthesis is indispensable. As regards to timing of reconstruction, several authors recommend phalloplasty to be undertaken around the time of puberty (10-14 years) in an effort to minimize the psychological trauma associated with genital inadequacy. All phalloplasty techniques use somatic tissue that is not hormone responsive and will grow proportionate with the rest of the body, thus near adult size phallus ought to be arranged while reconstruction. With advances in in vivo fertilization, having a child will be possible for these patients in future. 
Declaration of patient consent

The authors certify that they have obtained all appropriate patient consent forms. In the form the patient(s) has/have given his/ her/their consent for his/her/their images and other clinical information to be reported in the journal. The patients understand that their names and initials will not be published and due efforts will be made to conceal their identity, but anonymity cannot be guaranteed.

\section{Conclusion}

The neophalloplasty should be regarded as the preferred approach for boys born with aphallia, in opposition to female gender assignment. Aphallia is best managed by scrotal phalloplasty in the childhood which serves as a temporizing procedure followed by penile reconstruction at post-pubertal period.

\section{Financial Support and Sponsorship}

Nil.

\section{Conflicts of Interest}

There are no conflicts of interest.

\section{Bibliography}

1. Skandalakis JE., et al. "The male reproductive tract". In: Skandalakis JE, Gray SW, editors. The Embryonic Basis for the Treatment of Congenital Anomalies. Baltimore: Williams and Wilkins (1994): 733-77, 89-91.

2. Skoog SJ and Belman AB. "Aphallia: Its classification and management". Journal of Urology 141 (1989): 589-592.

3. Hage JJ and De Graaf FH. "Addressing the ideal requirements by free flap phalloplasty: Some reflections on refinements of technique". Microsurgery 14 (1993): 592-598.

4. Bajpai M. "Scrotal phalloplasty: A novel surgical technique for aphallia during infancy and childhood by pre-anal anterior coronal approach". Journal of Indian Association of Pediatric Surgeons 17 (2012): 162-164.

5. $\quad$ Langner RB and Redett R J. "Phalloplasty in Complete Aphallia and Ambiguous Genitalia". Seminars in Plastic Surgery 25 (2011): 196-205.

\section{Volume 2 Issue 9 September 2019} (C) All rights are reserved by Pradyumna Pan. 